\title{
Plant Bot: Intelligent Plant Application based on ADDIE Model of Instructional Design
}

\author{
Fifin Ayu Mufarroha ${ }^{1 *}$, Nizar Amir ${ }^{2}$, Dian Neipa Purnamasari ${ }^{3}$, Yudha Dwi Putra Negara ${ }^{1}$ \\ ${ }^{1}$ Department of Informatics Engineering, University of Trunojoyo Madura, 69162, Indonesia \\ ${ }^{2}$ Department of Mechanical Engineering, University of Trunojoyo Madura, 69162, Indonesia \\ ${ }^{3}$ Department of Electrical Engineering, University of Trunojoyo Madura, 69162, Indonesia
}

\begin{abstract}
Plant Bot is a mobile application is used as an aid for beginners and professionals to undertake farming activities. Users can use this app as a reminder of the time watering plants, and can add information to know the characteristics and handling of various plants. The purpose of this study is to improve the quality of public health by encouraging people to carry out physical activities in the midst of a pandemic and consume nutritious foods such as vegetables without preservatives from planting. There are 3 target users of the application, including students for educational materials, the general public to fulfill their food needs by farming and Advanced/Professional users such as farmers who want to make farming easier. The application development refers to the stages of the development life cycle in the ADDI model. The application that has been built has been running well, as evidenced by the results of testing based on functional requirements that can function as a whole.
\end{abstract}

Keywords: Intelligent Plant; ADDI Model; Mobile Application; Learning Media

\section{Introduction}

The development of information technology has advanced, characterized by several aspects of life have implemented the technology as a solution to facilitate the activity. One of them, the development of technology in mobile applications is growing very rapidly. In fact, mobile apps have trumped technology on websites [1]. The advantage of mobile applications is that the smartphone functions as a modern communication tool that is widely used and as a liaison with the community [2]. The rapid use of smartphones has an impact on the development of a variety of mobile applications [3]. Diversity can be seen in the development of mobile applications that cover several fields including tourism [4] [10], Music [11][12], Education [13][14], Health [15][16], and others[17][18][19]. Moreover, in 2019, an outbreak covid - 19 came and today has become a pandemic that is not yet known when it will end. The impact of COVID-19 is very broad, as long as the pandemic is not over it can affect people's behavior. At the same time, the humanitarian and safety aspects related to this pandemic have become a major issue of global concern, with social distancing restrictions, isolation and advice to stay at home. From this situation, it is obligatory for everyone to stay at home, work and do activities at home. All activities are carried out in a network by utilizing technology. Learning activities have shifted to using the Learning management system and office work has shifted to using online meeting rooms such as zoom, meet, and various other video conferencing applications. One of the things that need to be considered in this situation is to maintain health and continue to carry out physical activities in order to maintain body stamina and mental health. One of the steps that can be taken is to carry out planting activities. This activity is certainly done at home and can help the community about the importance of consuming healthy vegetables without preservatives. Additionally, due to the pandemic makes difficult to get food needs in the market or supermarket so by doing the planting of vegetables can help shop, which certainly healthy and fresh harvested themselves from yields. This can also help the educational process for children. However, farming activities require skills and knowledge of farming. Therefore, to help facilitate these activities, a mobile application called "PlantBot" was built. Plant Bot was developed for everyone who is interested in plants and wants to learn how to grow crops, so that users can understand how to care for plants, what plants need, and educate people about the uses and benefits of these plants. Plant Bot also provides a wealth of information about various types of plants that can be accessed by users. Users who have entered their plant data into the application will be made a schedule for plant care such as watering time and

\footnotetext{
* Corresponding author : fifin.mufarroha@trunojoyo.ac.id
} 
fertilizer application. Plant Bot will display a notification on the smartphone when it is time for plant care to be carried out. With the Plant Bot, it is hoped that it will have an impact on the wider community.

\section{Methodology}

In the development of intelligent applications using the ADDIE model. ADDIE model is a design model that implies simple and easy steps to study. This model can be applied in various kinds of application development . There are 5 main phases in this model including analysis, design, development, development, implementation and evaluation [20]-[24]. An illustration of the ADDIE model can be seen in Figure 1. Broadly speaking, the stages begin in the analysis phase where this phase focuses on finding application requirements using several data collection techniques. In addition, this phase wants to find answers to problems by conducting excavations. The design phase, converting the analysis results into application development. Application development in programming language and applied to the user's smartphone in the development and implementation phase. The final phase, evaluation is carried out to see the overall function of the application running perfectly.

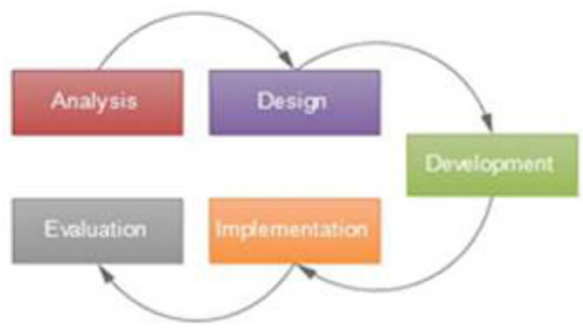

Fig. 1. ADDIE Model.

\section{Results and Discussion}

\subsection{Analysis}

To learn about users' understanding and experience about farming, especially growing crops, their knowledge of the types of crops, their daily activities, and their consumption of vegetables during the pandemic, this study recruited 5 professionals and 10 general public to conduct online interviews and conduct follow-up observations with them. By using these two techniques, the functional requirements of the application that are used as the basis for development are obtained. There are 3 target users of the application, including students for educational materials, the general public to fulfill their food needs by farming and Advanced/Professional users such as farmers who want to make farming easier.

\subsection{Design}

In this phase, design the functional requirements of the system that have been obtained in the analysis phase.
The interaction between the system and the user including the exchange of messages and activities carried out by the system can be seen in the use case diagram (Figure 2).

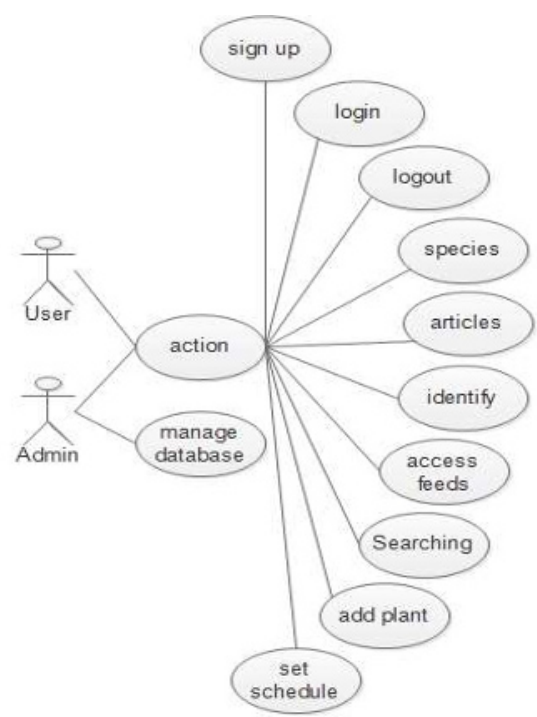

Fig. 2. Usecase Diagram

System actors are divided into 2 namely users and admins. The difference between the two users lies in the admin who can manage the database, while other activities can be carried out by the user and admin. Another diagram designed is a class diagram. Class diagrams are made to make it easier for developers and complement the use case diagrams in the development and implementation stages.

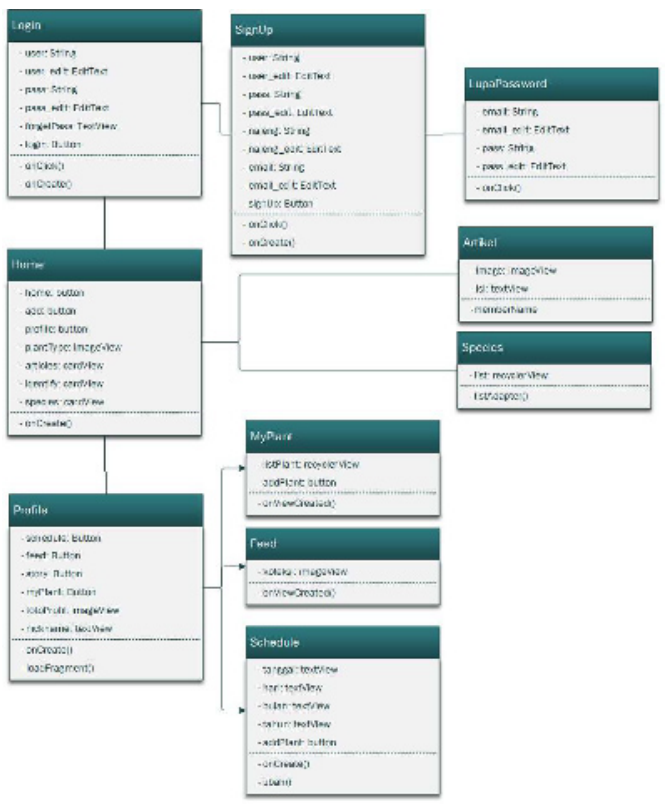

Fig. 3. Class Diagram 


\subsection{Development and Implementation}

Entering the application development environment where applications are developed based on mobile using a programming language that can be applied in smartphones. Application features are based on use case and class diagrams that have been designed and written with the help of Android Studio. Some of the system features can be seen in Figures 4 - 8 .

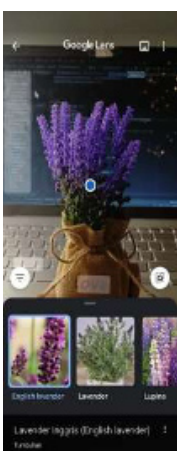

(a)

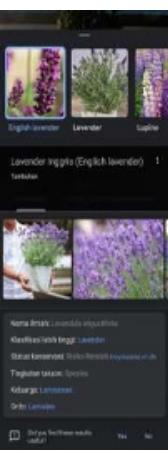

(b)

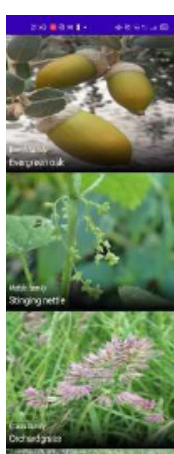

(c)

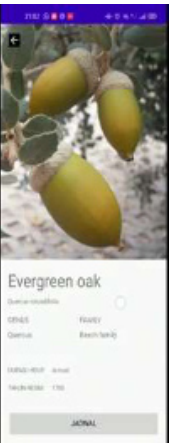

(d)
Fig. 4. Identify : (a)Capture Object (b) Result; Species Features (c) plant species (d) Detail

In the identification feature, users can find out details of plants that have not been identified yet. This feature the user will be directed to Google Lens and requires the camera focus on the crop object. As a result, the system will provide several image options for plant object recognition (Figure 3a). Based on these options, the user will select an image which will be directed to the plant detail page (Figure $3 \mathrm{~b}$ ). The species feature will display the types of databases that have been previously entered by the admin (3c). If the user selects one type of plant on the page, the system will display information ranging from the image of the plant, the name of the plant, the genus, quercus, duration of life, and the year the plant was inaugurated (3d).

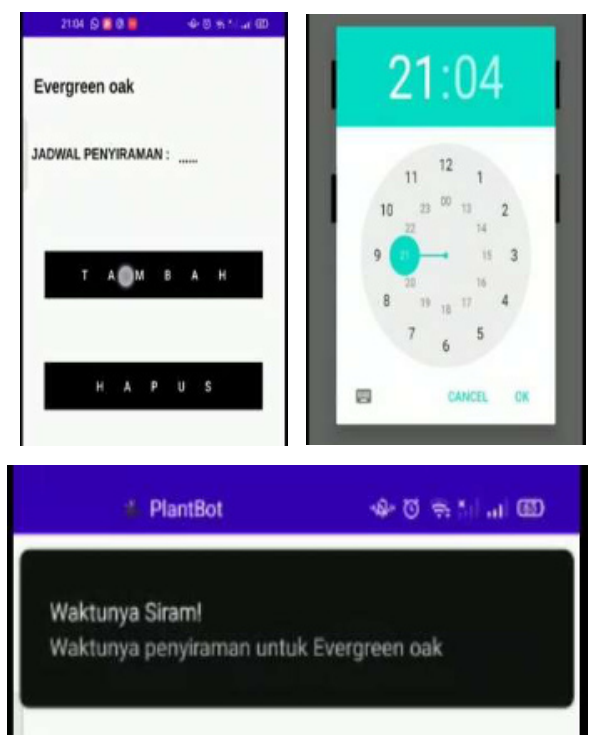

Fig. 5. Scheduling.
The watering schedule serves as a reminder for watering. The reasons given for scheduling are often neglected about the importance of water for plants, several types of plants have different times, and the lack of public understanding. the application will provide a notification on the smartphone screen as a marker of the watering schedule. Before accessing all the features, users need to login first as shown in Figure 6. Users who have gone through the login page will be directed to the home page which displays the types of plants that the user can choose according to their choice (Figure 7)
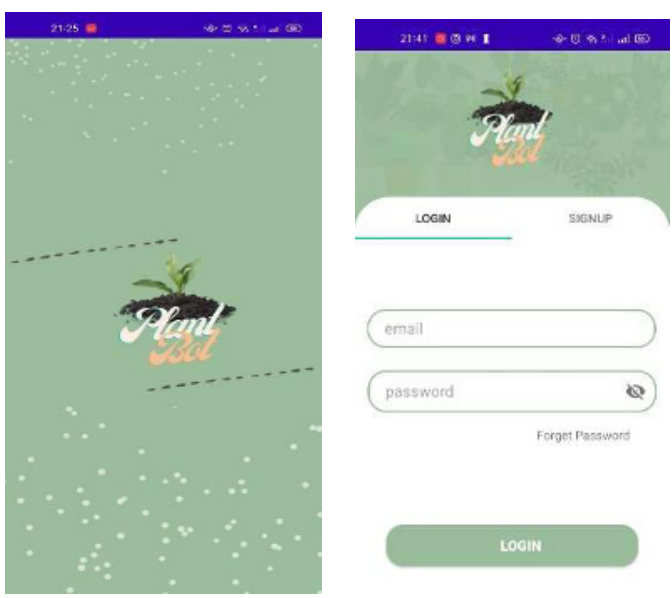

Fig. 6. Start page and login
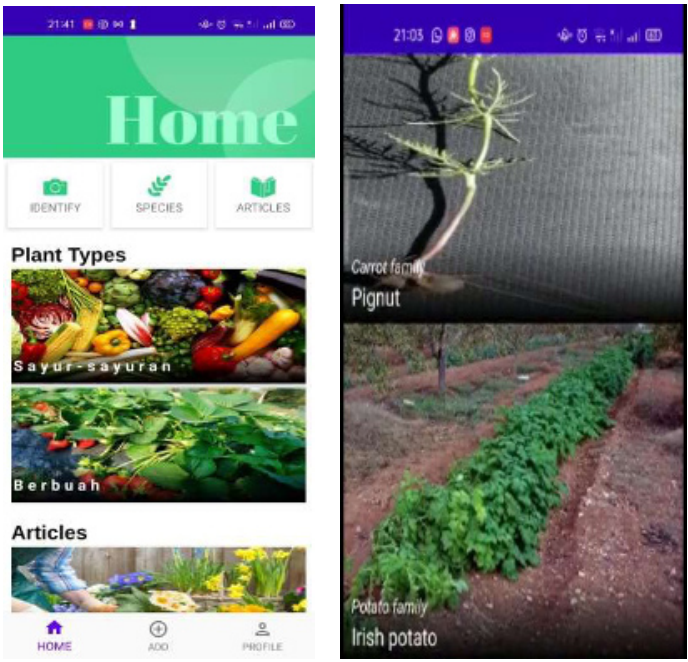

Fig. 7. Home

\subsection{Evaluation}

To find out the function of the system is running well, it is necessary to evaluate it. measurement of the success of the system function is done by testing the functional requirements of the system. Table 1 is a table that lists functional requirements that have been evaluated. Based 
on the evaluation results, it can be seen that the application is running well.

Table 1. Functional Requirement Test.

\begin{tabular}{|c|c|}
\hline Use Case & Requirement \\
\hline Sign Up & Users can register into the PlanBot \\
\hline Login & $\begin{array}{c}\text { Users can log in by entering the } \\
\text { username and password they already } \\
\text { have in their PlanBot account to access } \\
\text { the system. }\end{array}$ \\
\hline Logout & Users can exit the PlantBot \\
\hline Species & $\begin{array}{c}\text { Users can find out information about } \\
\text { plant names registered in the PlantBot } \\
\text { application. }\end{array}$ \\
\hline Articels & $\begin{array}{c}\text { Users can find out various kinds of } \\
\text { information about plants through the } \\
\text { articles presented. }\end{array}$ \\
\hline Identify & $\begin{array}{c}\text { Users can identify plants that are directed } \\
\text { to the Google Lens application to find } \\
\text { out information about these plants. }\end{array}$ \\
\hline Access Feed & $\begin{array}{c}\text { Users can view user posts and upload } \\
\text { photos }\end{array}$ \\
\hline Searching & $\begin{array}{c}\text { Users can browse plant information by } \\
\text { plant type }\end{array}$ \\
\hline Manage \\
Database
\end{tabular}

\section{Conclusion}

Intelligent application for farming can be used as a tool in gardening for beginners or even the professional level. Users are facilitated with various features such as types of plants, articles, adding photos, identifying plants that are not yet known, and many other features. In addition, this application can also be used as education for students in understanding the types of plants and plant body parts. This application runs well after being tested through the success of all the functional requirements of the system can run. future application development by making improvements to the application.

\section{References}

[1] Sunardi, G. F. P. Desak, and Gintoro, "List of Most Usability Evaluation in Mobile Application: A Systematic Literature Review," in 2020 International Conference on Information Management and Technology (ICIMTech), (2020), pp. 283-287, doi: 10.1109/ICIMTech50083.2020.9211160.

[2] A. Jauhari and F. A. Mufarroha, "Smart Mobile Application for Decision Support Systems on Determination of Resident in Dormitory," $J$. Ilm. Kursor, vol. 10, no. 3, pp. 135-144, (2020), doi: 10.21107/kursor.v10i3.236.

[3] A. Kaya, R. Ozturk, and C. Altin Gumussoy, "Usability Measurement of Mobile Applications with System Usability Scale (SUS) BT - Industrial Engineering in the Big Data Era," (2019), pp. 389-400.

[4] A. Jauhari, F. A. Mufarroha, M. Rofi', M. F. Nasrullah, Fitriyah, and K. Nisa, "The Development of Smart Travel Guide Application in Madura Tourism," vol. 473, no. Icss, pp. 771-776, (2020), doi: 10.2991/assehr.k.201014.167.

[5] M. Afzaal, M. Usman, and A. Fong, "Tourism Mobile App With Aspect-Based Sentiment Classification Framework for Tourist Reviews," IEEE Trans. Consum. Electron., vol. 65, no. 2, pp. 233-242, (2019), doi: 10.1109/TCE.2019.2908944.

[6] D. Mayordomo-Martínez, J.-C. SánchezAarnoutse, J. M. Carrillo-de-Gea, J. A. GarcíaBerná, J. L. Fernández-Alemán, and G. GarcíaMateos, "Design and Development of a Mobile App for Accessible Beach Tourism Information for People with Disabilities," International Journal of Environmental Research and Public Health , vol. 16, no. 12. (2019), doi: 10.3390/ijerph16122131.

[7] R. Safitri, D. S. Yusra, D. Hermawan, E. Ripmiatin, and W. Pradani, "Mobile tourism application using augmented reality," in 2017 5th International Conference on Cyber and IT Service Management (CITSM), (2017), pp. 1-6, doi: 10.1109/CITSM.2017.8089305.

[8] C. Ceccarini and C. Prandi, "Tourism for all: a mobile application to assist visually impaired users in enjoying tourist services," in 2019 16th IEEE Annual Consumer Communications \& Networking Conference (CCNC), (2019), pp. 16, doi: 10.1109/CCNC.2019.8651848.

[9] A. Smirnov, A. Kashevnik, N. Shilov, N. Teslya, and A. Shabaev, "Mobile application for guiding tourist activities: tourist assistant TAIS," in Proceedings of 16th Conference of Open Innovations Association FRUCT, (2014), pp.95-100,doi: 0.1109/FRUCT.2014.7000931.

[10] S. K. Viswanath, C. Yuen, X. Ku, and X. Liu, "Smart Tourist - Passive Mobility Tracking Through Mobile Application BT - Internet of Things. IoT Infrastructures," (2015), pp. 183191.

[11] B. Rusyn et al., "The Mobile Application Development Based on Online Music Library for Socializing in the World of Bard Songs and Scouts' Bonfires BT - Advances in Intelligent Systems and Computing IV," (2020), pp. 734756.

[12] M. Rusiñol, J. Chazalon, and K. Diaz-Chito, "Augmented songbook: an augmented reality educational application for raising music awareness," Multimed. Tools Appl., vol. 77, no. 11, pp. 13773-13798, (2018), doi: 10.1007/s11042-017-4991-4.

[13] A. Bakhouyi, R. Dehbi, and M. Talea, "Toward 
an Adaptive Architecture for Integrating Mobile Apps with LMS using Next Generation of SCORM," in 2019 2nd International Conference on Computer Applications \& Information Security (ICCAIS), (2019), pp. 1-7, doi: 10.1109/CAIS.2019.8769575.

[14] R. D. Banimahendra and H. B. Santoso, "Implementation and evaluation of LMS mobile application: scele mobile based on usercentered design," J. Phys. Conf. Ser., vol. 978, p. 12024, (2018), doi: 10.1088/17426596/978/1/012024.

[15] L. F. Mieras, A. T. Taal, E. B. Post, A. G. Z. Ndeve, and C. L. M. Van Hees, "The Development of a Mobile Application to Support Peripheral Health Workers to Diagnose and Treat People with Skin Diseases in Resource-Poor Settings," Tropical Medicine and Infectious Disease, vol. 3, no. 3. (2018), doi: 10.3390/tropicalmed3030102.

[16] C. Yefta, "Aplikasi pengenalan karakter BISINDO menggunakan convolutional neural network dengan single shot multibox detector," (2019), [Online]. Available: http://repository.uph.edu/5605/.

[17] A. Balapour, H. R. Nikkhah, and R. Sabherwal, "Mobile application security: Role of perceived privacy as the predictor of security perceptions," Int. J. Inf. Manage., vol. 52, p. 102063, (2020), doi:https://doi.org/10.1016/j.ijinfomgt.2019.10 2063.

[18] A. Kashevnik, I. Lashkov, and A. Gurtov, "Methodology and Mobile Application for Driver Behavior Analysis and Accident Prevention," IEEE Trans. Intell. Transp. Syst., vol. 21, no. 6, pp. 2427-2436, (2020), doi: 10.1109/TITS.2019.2918328.

[19] A. Tarute, S. Nikou, and R. Gatautis, "Mobile application driven consumer engagement," Telemat. Informatics, vol. 34, no. 4, pp. 145156,(2017),doi:https://doi.org/10.1016/j.tele.20 17.01.006.

[20] K. Rosyidi, D. S. Kudori, and A. A. Supianto,
"Design and Development Educational Media Diction of Madurese Language Level," 3rd Int. Conf. Sustain. Inf. Eng. Technol. SIET 2018 Proc., pp. 180-185, (2018), doi: 10.1109/SIET.2018.8693185.

[21] F. G. Constancio et al., "Extended ADDIE Model for improved Distance Learning Courses," in 2018 IEEE Frontiers in Education Conference (FIE), (2018), pp. 1-5, doi: 10.1109/FIE.2018.8658925.

[22] D. R. Hidayanto, Munir, E. F. Rahman, and J. Kusnendar, "The application of ADDIE model in developing adventure game-based multimedia learning to improve students' understanding of basic programming," in 2017 $3 r d$ International Conference on Science in Information Technology (ICSITech), (2017), pp. 307-312,doi:10.1109/ICSITech.2017.8257130.

[23] R. S. Nadiyah and S. Faaizah, "The Development of Online Project Based Collaborative Learning Using ADDIE Model," Procedia - Soc. Behav. Sci., vol. 195, pp. 18031812, (2015), doi: https://doi.org/10.1016/j.sbspro.2015.06.392.

[24] S.-J. Yu, Y.-L. Hsueh, J. C.-Y. Sun, and H.-Z. Liu, "Developing an intelligent virtual reality interactive system based on the ADDIE model for learning pour-over coffee brewing," Comput. Educ. Artif. Intell., vol. 2, p. 100030, (2021),doi:https://doi.org/10.1016/j.caeai.2021. 100030. 